\title{
Decentralization management in the context of Chinese history and modern financial services
}

\author{
Kai CHEN ${ }^{1}$ \\ ${ }^{1}$ Babes-Bolyai University, Romania
}

\begin{abstract}
The exploration of centralized and decentralized governance never stops along Chinese history from the agricultural and feudal society to modern digitalized ecosystem nowadays and the conflict between these two managerial ideologies in Chinese history is a conflict restricting but supporting each other. With the emergence of Bitcoin and the deployment of blockchain technology which is the technical infrastructure of encryptcurrencies, decentralized management attracted attention from various industries and domains especially traditional financial system. The practice of blockchain in payment, settlement, supply chain, insurance and other domains is in a critical moment with support from government and regulations. As the heterogeneity of social ideology and overall productivity in feudal society and contemporary society, we can understand the relationships between economy and managerial models, centralization and decentralization, and try to find efficient strategies challenges in decentralized management based on blockchain technology. Besides the thought-provoking changes brought by blockchain in financial services with the attractive characteristics including decentralization, transparency and immutability, the practical problems in deployment require people to do more research and experience new strategies. This paper aims to analyze the decentralization management based on Chinese history and modern financial services with theoretical study and analysis from the perspective of historical and economic development related to blockchain-enabled centralization and decentralization. With analysis of the application of blockchain in financial services, a better understanding of decentralization management is visible and meaningful for further research of blockchain technology-related projects.
\end{abstract}

Keywords: Decentralization, Centralization, Blockchain technology, Chinese history, financial services

\section{Introduction}

The dialectical thought applies to the antithetical attitude between Confucianism and Legalism in Chinese cultures, the paradox of openness and privacy in information management, as well as the relationship between centralization and decentralization in history. In Chinese, there is a sentence “分久必合,合久必分” which means the history of society obeys the rule that separates after long unification and unites after separation. In social ideology, this is the paradoxical relationship of centralization and decentralization. Rousseau (1762) claimed that man is innately good and should be given the tools to achieve perfection, and his Social Contract is the foundation of all legitimate authorities established in a decentralized model where the combination of every single man makes full use of their rights to the protection of people's freedom. This social governance is a typical decentralized governance. But the "social contract" of Hobbes (1651), who claimed that man was innately evil and need someone (a manager) to centralise and guide him. The natural basic state of humankind is one of anarchy. In this way, the social governance is in a centralized model and it applies to many societies for thousands of years in China and western countries. Here we have to make it clear that both centralized and decentralized governance have their strengths as well as weaknesses. The economic formation of society, productivity, and social ideology in a period can determine the governance way and the degree of decentralization. Maintaining the balance between the two and using their advantages to improve management are the goals for managers rather than neglecting one approach and only using the other.

The strength of centralization is the explicit union of justification, management, and high efficiency in work with the best use of all available resources; the weakness

\footnotetext{
* Corresponding Author. Phone: 40732601415

E-mail: kane201086@hotmail.com
} 
is complex procedures influenced subjectively and the lack of restriction in power. Decentralization can make up for the weaknesses of centralization. Many wars were between two different autocratic forces, while wars are also used as the tools to explore democracy and freedom against autocracy and dictatorship. Autocracy is a symbol of centralization beneficial to social development at beginning while its problems gradually appeared. The development of decentralization follows the rules of history. Decentralization is challenging to achieve economically in a feudal society due to the limitations of the economic situation, population and technology.

Nevertheless, in the current financial system, the situation changed with the blockchain technology which brought surprising changes in many industries and people's future. In digital age, traditional management has difficulties in meeting the demands for openness, interoperability and decentralization of the Industrial 4.0 blockchain-based management of financial and other domains; new challenges require new approaches (Liu et al., 2019).

Trust is based not on explicit evaluations but on emotional responses and it is an intuitive, unconscious appraisal. Trust has three layers which are systematically related with each other in natural language and in the scientific literature. It is a mere mental attitude (prediction and evaluation) towards another individual or an agent. It is a decision to rely upon the other and it is a behaviour showing trust between the trustor and the trustee (Castelfranchi, 2004). Blockchain is a distributed ledger recording all executed transactions, and arguably the critical technology in changes the paradigm of trust that has existed for centuries whereby centralized institutions provide trust in our transactional systems (Niekerk, 2016). Blockchain technology is organized in a linear sequence of smaller encrypted datasets called 'blocks', which contain timestamped batches of transactions. Each block contains a reference to its preceding block and an answer to a complex mathematical puzzle, which validates the transactions it contains (Pazaitis et al., 2017). The advantages of this new technology including transparency, openness, and immutability, indicate the potential to become a new foundation for decentralized business models that reduce transaction costs, generate distributed trust, and empower decentralized platforms (Chen and Bellavitis, 2019).

This technology allows the disintermediation and decentralization of all transactions of any type between all parties on a global basis (Swan, 2015). Decentralization brings decision-making in several aspects closer to the people and therefore yields programmers and services that better address local needs (Work, 2002). Furthermore, it is a source for bottom-up participatory development, improving local governance and resulting in poverty reduction in rural areas (Ahmad and Talib, 2011). The financial services are an area where decentralized reforms are happening, such as the tax reform in 1994 and the policies to promote the development of local infrastructures in China.

This paper is developed from the work presented in IMSS'19. The demonstration of the development of decentralization in different periods and the conflict with centralization in Chinese history are examined objectively together with the advantages and disadvantages of centralization and decentralization. The impact of centralization and decentralization to the economic growth and social development before, in feudal society, and contemporary Chinese financial service embodies tendency of decentralization. Based on the previous content, the theory knowledge of centralization, decentralization, blockchain technology is elaborated with more references from published articles, academic database, and several researchers and people working in blockchain projects. We add more analysis of the deployment of blockchain technology in financial area with comparisons between traditional and innovative blockchain-enabled payment, settlement as well as the insurance industry and securities domain. After the analysis, we present the suggestions for better understanding of the relationship of centralization and decentralization, the strategies dealing with the problems in decentralized blockchain projects in financial services.

\section{Types of Decentralization}

Decentralization has been an essential part of the economic growth of society as it tends to produce more democracy and efficiency. Whether in developing or developed countries, decentralization reform happens administration and finance. Generally speaking, there are four types of decentralization, including political, administrative, fiscal, and market decentralization.

Political decentralization means the power in the hands of a small group of people can be parcelled out to more people who are citizens or selected by citizens. Pluralistic politics and representative government are the characteristics of it. The decision made by more people can get more common ideas from citizens and meet the diverse interests from differential economic strata.

Administrative decentralization means the redistribution of authority and resources. Some functions are removed from the central government to local governments, subordinate units, related departments and organizations that are more familiar with the local situation. The traditional complicated organizing procedures are simplified or even eliminated for a high-efficiency administration in different areas.

Financial decentralization is the most popular and attractive type of decentralization as the result of its implementing reflects the economic development and social life most directly. Fiscal decentralization can take many forms, including 
a) self-financing or cost recovery through user charges;

b) co-financing or co-production arrangements through which the users participate in providing services and infrastructure through monetary or labour contributions;

c) expansion of local revenues through property or sales taxes, or indirect charges;

d) intergovernmental transfers that shift general revenues from taxes collected by the central government to local governments for general or specific uses;

e) authorization of municipal borrowing and the mobilization of either national or local government resources through loan guarantees (Fye, 2017).

Market decentralization is the ultimate goal of decentralization where the centralized organization gives the function of managing every aspect of the economy and the society to the market or economy. Private companies, community groups, cooperatives, and other non-government organizations have rights and responsibilities to make good decisions for market development. The power of government is almost equal to every private unit.

At present, the political and market decentralizations are impossible to achieve at the social and economic development levels. We should focus more on the benefits of administrative and fiscal decentralization deployment. For administrative decentralization, many policies and measures have been taken by the central government and organizations to maximize the advantages of local government, who are more familiar with the actual situation in various areas. Fiscal decentralization has also benefitted from practice. In the practice of decentralized management, centralized management is still keeping its essential role which is not replaced by decentralization.

For decentraliztion, according to the degree of decision rights of every members or department, it can be divided into three degrees: devolution, delegation and deconcentration.

- Devolution is the complete decentralization, and the power is decentralized from the management group to all members or departments.

- In delegation, the right to decide is divided between several semi-autonomous organizations.

- In deconcentration, the decision right is divided among other organizations, but the management class has the most rights (Buterin, 2017).

With the Blockchain and other cryptographic monies, the decentralization in internet technology and financial services should have different meanings. According to Burterin (2017), there are three separate axes of centralization/decentralization that are independent of each other:

1) Architectural decentralization,

2) Political decentralization,

3) Logical decentralization.

Architectural decentralization means the number of physical computers in a blockchain system and the breaking down of some computers can still allow the blockchain work normally. Political decentralization is pertinent to individuals and organizations that manage and control the blockchain project system. In logical decentralization, the interface design and data structure should be like an amorphous swarm, and when the system is split into several parts, it can still have a function as independent units.

\section{Development of Decentralization}

There is a tradition about the earliest decentralization in the world, which happened before the historical origin of humans. The tradition states that the plants practised decentralization for survival. The plants' way of living can be seen as a decentralized model, while animals embody centralization: in order to live in a poor environment and in the competition with animals, plants gradually make themselves live in a decentralized model which means every plant cell can restore and restart when animals eat some plants part; whatever is left can restore and regrow. There is not an organ like an animal's brain to control all the other body organs and actions. The central animal brain gives orders and controls all the other body parts: the body structure is centralized. If the brain is damaged, the whole body suffers.

Both plants and animals have pros and cons. With centralization, animals have a relatively rapid reaction to stimulations and dangers, and powerful strengths in all body parts. However, if the central brain is damaged, the other parts, no matter how powerful they are, lose control and become nothing. Plants have slow reactions to dangerous stimulation but remain alive even after the destruction of some parts. Compared to the centralized development, decentralization is a very long and challenging process, whether in the evolution of plants or the research of blockchain application now. The most challenging issue comes from the emotional culture when people conduct decentralized governance in blockchain projects. Many practical questions are too complicated to use quantitative methods to solve.

In modern society, the conflict between centralization and decentralization is embodied in more diverse forms, and the internet field and financial services illustrate the struggle between the two managerial models. In the book Out of Control: The New Biology of Machines, Social Systems, and the Economic 
World by Kelly (1994), the distributed internet and decentralization has been mentioned and explained in detail: there is no mandatory centralized control; intelligence is not organized in a centralized structure, but more like a bee-hive of small, simple components, with robust connections between them (Kelly, 1994). The first deployment of blockchain technology in payment appeared in 2009 by means of Bitcoin that is a peer-to-peer payment system. Nowadays, blockchain technology has made the decentralized financial system come true with the peer-to-peer value transaction, distributed databases, distributed ledgers, smart contracts, and encrypted digital currencies. The core of blockchain technology is to have a distributed ledger in an asymmetric internet-based world through encryption algorithms rather than the endorsement from government or business. It is important to understand that decentralization is only a method and a process rather than the utmost goal of management. It is an innovative ideology that currently replaces centralization to have high efficiency and low cost in both management and production, and to achieve the goal of disintermediation.

\subsection{Decentralization in Chinese History}

In this chapter, we will analyze the centralization and decentralization situation in Chinese history based on the unified period and disunified periods. During the unified periods, the central autocratic government is the centralized authority which controlled the economy, policies, cultures, and other aspects. It is the typical political administration and fiscal centralization. While during the disunified periods, there existed several authorities which are equal to each other. There is no central government managing. Figure 1 illustrates how centralized government and decentralized organizations work.
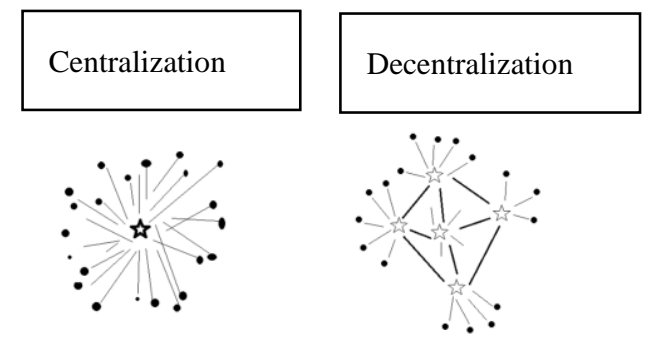

(Source: Author's own presentation)

Figure 1: The images of Centralization and Decentralization

In Chinese history, many unified dynasties were established in the form of monarchy. In those periods, the emperor is the only centre, controlling and making all decisions regarding finance, education, administration, and many other aspects. Between the unified periods, many years are in apparent anarchy but several authorities existing at the same time. They had wars with each other while also have cooperation in trade, agriculture, and culture. The relationship is like the patterns in figure 1 . The following table demonstrates centralized and decentralized situation of feudal societies throughout Chinese history including Anno Domini (AD) and Before Christ (BC). The blue column means the unified dynasties and the red column refer to disunified periods.

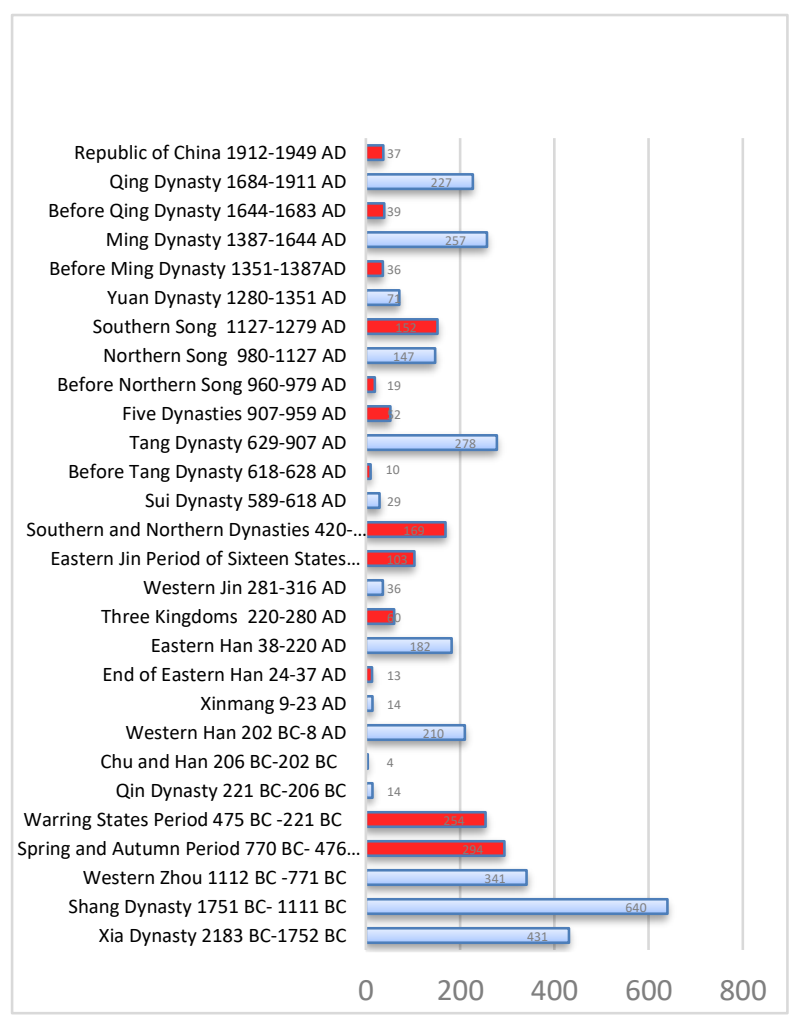

(Source: Author's own presentation, based on information available from Lü, 2016)

Figure 2. The Unified Periods and Disunified Periods in Chinese History

The total number of years examined is 4119 , of which 2877 unified years and 1242 disunified years. The percentage of unified years is $69.85 \%$, that of disunified years is $30.15 \%$ : the centralized period is two times more than the decentralized period. How is the economic situation in the centralized period? The following table shows the Gross Domestic Product (GDP) in several prominent unified dynasties. 
Table 1. The Economic Situations in Different Chinese Dynasties

\begin{tabular}{lllc}
\hline $\begin{array}{l}\text { Dynasty } \\
\text { name }\end{array}$ & Time & Population & $\begin{array}{l}\text { GDP } \\
\text { percentage } \\
\text { of the world }\end{array}$ \\
\hline Han & 202 BC-220 AD & $60,000,000$ & $26 \%$ \\
Sui & $589-618 \mathrm{AD}$ & $50,320,000$ & $70 \%$ \\
Tang & $629-907 \mathrm{AD}$ & $80,500,000$ & $58 \%$ \\
Northern & $980-1127 \mathrm{AD}$ & $126,000,000$ & $80 \%$ \\
Song & & & \\
Yuan & $1280-1351 \mathrm{AD}$ & $90,000,000$ & $28 \%$ \\
Ming & $1387-1644 \mathrm{AD}$ & $200,000,000$ & $55 \%$ \\
Qing & $1684-1911 \mathrm{AD}$ & $436,000,000$ & $35 \%$ \\
\hline
\end{tabular}

(Source: Author's presentation based on information available from Lü, 2016)

During centralized feudal dynasties, the central government made decisions regarding the fiscal questions. The centralized economy was very efficient for economic growth. The percentage of GDP to the whole world shows the advantage of the centralized economic system. Local governments and departments implemented the policies made by the central government. So, if the central government made a correct decision, society progressed in economic growth because the decision was final and no organization could interfere.

Nevertheless, if decisions from the central government were incorrect or not suitable for the current situation, the result was stagnancy. Fortunately, the prosperous dynasties learnt from previous dynasties' experiences enough to make the right decision in most cases, and emperors tried to accept suggestions from officials. In the following part, we can have a better understanding of the centralized economy in feudal society.

\subsection{Decentralization in the history of the Chinese economy}

In ancient times, before feudal society, Chinese society was working based on a natural economy which relied on agriculture. The ownership of land was the dominating factor for economic development. Humans connected through agricultural labours and worked together for the common goal of having enough food for personal life rather fight for ownership of more food or land. The concept of the individual was much less the ideology than that everything belonged to the public good.

In that agricultural economy, the Well Farmland System was deployed to divide the land for agricultural work. The system name comes from the pattern of land division which was similar to Chinese character 井, and it means the well. In this system, a piece of land would be divided into nine parts of approximately 100 acres each. The middle part was public, and the others were private. Harvest from private land belonged to people themselves, and the food from the public part helped the families who did not have enough harvest. Although the land was divided between individuals, essentially it was a public system, and the previous division was cancelled after 3 years and reassigned. Besides the public land, there were public houses where people could stay after working in the fields. Older people supervised the work and daily life. No matter whether they worked in the fields or cooked in the public house, people helped each other without material purpose.

As the industry had not emerged yet, agricultural tools and other daily tools were easy to make, and the small number of families limited the demand for business. People producing the tools did not start businesses, and their income came from others' help and donations. The exchange of agricultural tools was only for basic needs not for commercial profit, so there was no business or trade during that period.

This economic model was the result of smallscale economy and social ideology, as well as the population. It is hard to define whether that period was more decentralized or not as society was not mature enough to establish a complicated social structure, and the concept of decentralization and centralization are connecting to more developed productivity.

With the increase of population and the development of agricultural technology, immigration and the population flow prompted further communication between nations. Because civilization developed fast and people had more power in fighting with nature, conflicts appeared between different nations, classes, and groups. Conflicts came with trade between people. Trade necessitated communication, and they guided society to more centralized structures as profit was gathered by a small number of people who composed the dominant hierarchy.

Gradually, feudalism came into being, and centralization became the primary model in production. Centralized feudalism was the production of an agriculture economy. Conversely, it was involved in the agricultural economy as it possessed the following properties:

1) People in agricultural communities longed for a peaceful and stable life; they did not like or want to have food through looting.

2) The possessions in agricultural society were land and agricultural tools which were heavy and hard to remove. People preferred to live in the same land rather than move to other places.

3) Compared to the power of a nomadic nation who travelled and got used to loot, the agricultural nations had less power to defend (Zhang et al., 2015).

As a result of the agricultural economy, feudal society was formed by the group who had the power to govern the others, and the dominant hierarchy and ruling classes were gradually formed. The economic system 
and social structure were centralized to meet the need for productivity.

In the feudal society in ancient China, centralization had the absolute dominating position even if the peasant people needed decentralization which was not suitable for the society at that moment. Nevertheless, the balance between these two ideologies or social structures was in a subtle relationship. First, the dominance hierarchy, which was the representative of centralization, should leave space for ruled peasants in order to have a sustainable ruling group and stable society. Second, the purpose of governance by the dominance hierarchy was to have profit from ruled class, too much interference and strict management would outbreak conflicts. When centralization achieved the extremity, decentralization was considered by most people. Third, the power by dominance hierarchy, to some degree, was offered by ruled people. The centralized social ideology was the tendency of productivity development. When society continues to develop, and the economy achieves higher levels, the request for decentralization becomes stronger, and more suitable for the demand of the digital age. In any time, coexistence is significant for these two ideologies.

The invention and development of the currency contributed to capital centralization (Lü, 2016), and trades and business made economy develop faster. Profits were centralized in the group of landlords, businessmen, and bankers. In this period, value transaction has replaced the division of land and other materials assistance for each other. The conflicts between centralized governance and free division of resources worsened, and the competition between centralization and decentralization became fiercer than previously. Some scholars and officials tried to recover the former production systems, in which the land and profits were divided, and people helped each other without profit-related purposes. Among those reforming ideologies, Confucianism and Legalist school were the main ideologies that won support from most people. Both of them tried to implement more decentralized measures in fiscal management; nevertheless, their methods were different. Confucianism believed that the land-right should be averaged and every peasant could own the land. The Well Land System was a good option. The Legalist school advocated further control of the development of capitalism: the government managed the primary trades and controlled all borrowing. Neither of them helped the economy develop better because Confucianism did not understand that the domination hierarchy was the group enjoying the profit from ruled groups, and they would not consider stopping the profits and return them to the peasants. The Legalist school did not consider the position of the groups of businessmen asking for a freer business environment. The market was the primary influence on the need for real economic development. Only when the needs and profits from both groups achieved a balance, namely centralized and decentralized management were utilized effectively, could the Chinese economy and society that time be promoted.

In the 20th century, with more development of the economy, inequality of wealth became more serious. The imperial government was not capable of solving this problem and averaged wealth to a relatively good degree. The inequality in resource division directly resulted in different kinds of social problems, and the autocracy in Chinese feudal government made this problem more serious. At last, the economy needed an adjustment in management. Since the Qing government, the last feudal dynasty was forced to open the gates of the nation, the economy in China transferred from natural economy to capital-based economy, and decentralized fiscal mechanisms were applied in increasing degrees. In recent years, with the growing utilization of blockchain technologies, decentralized mechanisms came into the spotlight. After a long time of centralized financial services system, customers are looking for a more convenient, efficient and secure decentralized financial system. The application of Blockchain in financial services no doubt is the attempt attracting attention from all around the world.

\subsection{Decentralization in modern financial service}

In the digital world, value is embodied by digitalized currencies, and payments are processed through centralized banks and financial organizations. Since the invention of online payment, the centralized payment method is utilized along the time. The change appeared when the Bitcoin appeared and the popularity of Blockchain technology. In the region of financial sector, the savings from blockchain-enabled technologies achieve tens of billions of US dollars annually with 1112 billion US dollars annually on the settlement of cash securities alone (Schneider et al., 2016).

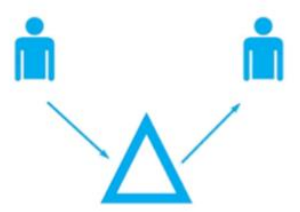

Figure 3. The centralized value transaction model with fiat money

(Source: Author's own presentation)

In a typical centralized payment, all payments and value transfers have to be managed and processed by centralized organizations, such as banks, PayPal company, Ali Pay companies, which is presented by figure 3. The private information of customers and companies are stored by those organizations with the risk of private data lose. Even though there is a trusted 
endorsement for security and privacy, the risk of illegal stealing and commercializing of information remains.

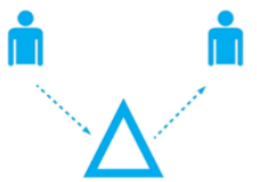

Figure 4: The centralized value transaction model with virtual currencies

(Source: Author's own presentation)

Figure 4 demonstrates the model that traditional value carrier currencies changed by electronic money, which is issued and endorsed by business companies, and it is used exclusively among that company's products. This model improved the efficiency of trades but has the risks of information leakage. It is a centralized payment method.

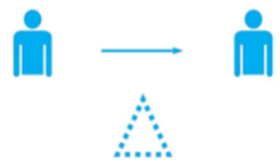

Figure 5: The decentralized value transaction model with blockchain technology

(Source: Author's own presentation)

Figure 5 embodies the decentralized model allowing value transfers to be completed in an ideal peer-to-peer way without the interference of third party. People can transfer value directly from one actor to the other actor. Empowered by blockchain technology, decentralized financial services have the potential to broaden financial inclusion, facilitate open access, encourage innovation to reduce commission, and create new opportunities for entrepreneurs and innovators (Chen and Bellavitis, 2019).

Here we can compare the structures mentioned above in currency issue, value creation, value-adding, and transactions.

In the currency issue, fiat money in current centralized financial system is the only legal currency in circulation, issued by the government. In a digital society, virtual currencies are credits and tokens in particular games, programs and virtual communities. They are issued by companies and used for the relevant company products only. In a decentralized financial system based on blockchain technology, the currency used is named crypto-currency and is based on cryptography. It is issued without the interference from third-party.
About value creation and value-adding, fiat money in centralized financial systems has no value; the value is created and added using the connection with valuable products, exchanges of products and technologies. Many factors influence the value of fiat currency. The value for virtual currencies comes from the number of customers and the market scale, but businesses rather than customers manage the scale. The value in blockchain projects is created and added by the frequent deployment of decentralized service and products. The more customers use the service, the more value is created and added with less control from the centralized business or government.

Value transactions such as payment, at present, are performed by centralized financial organizations with government endorsement. The efficiency is expected to improve, and the cost is expected lower. Transaction of virtual currencies is also centralized. The issue companies are centralized entities managing the proper transaction. In a decentralized financial system, it is processed between two persons or organizations without interference from a third party, so the efficiency is improved and the cost is lowered.

If we take Bitcoin as an example, the total number of Bitcoin is limited and new Bitcoins are issued by solving mathematic problems in a relatively complicated level. The transaction of Bitcoins is decentralized without the interference of banks or financial organizations. It has no direct connection with fiat currencies. There are other decentralized financial systems similar to Bitcoin, and they are working from the first stage of automation to more advanced stage that will work autonomously with smart contract, which a software program that adds layers of information onto digital transactions being executed on a blockchain (Chatsko, 2018). Then, the issue and transaction shall be even more autonomous and secure.

Decentralization is the most significant characteristic of blockchain technology; it makes blockchain and its related organizations stand out from traditional management structures. It means that every member of the blockchain structure has access to the whole distributed database. Opposed to the centralbased system, consensus algorithm allows for control of the network (Anastasiia, 2019), blockchain offers every participant the opportunity to establish consensus without assuming mutual trust by implementing a single coherent data chain shared amongst a set of non-trusting participants, which acts as a single point of truth. Critically, no privileged parties are required to maintain the ledger but all participants have the responsibility to maintain and protect the data(Müller et al., 2017). Cryptography rather than traditional credit makes all the rules clear and easy to follow in blockchain. In the traditional centralized management, a central block is the key of all the information system, once this central block is hacked or attracted, the stored data will get lost, and users suffer. While this situation is hard to happen 
in blockchain system as only the control of more than half the existing blocks can change the data, which is too costly to do.

\subsection{A decentralized payment and settlement system with blockchain technology}

The payment process usually includes two main parts: payment method and settlement. The settlement process is complete following the final transfer of assets from the seller to the buyer and payment is the final transfer of from the buyer to the seller to transfer money, goods or services in the form of cash, check, wire transfer, credit card and so on (Bott \& Milkau. 2017). In modern financial world, common payment methods mainly include cash payment, bank transfer, credit card payment, and Internet-based mobile payment, such as Alipay, WeChat Pay, PayPal, Apple Pay, etc. Payer and receiver together decide the payment method. With the maturity of technologies such as the Internet and Nearfield Communication (NFC), payment methods have gradually become more optimized and convenient. The application of blockchain technology is mainly in payment and settlement. No matter what payment method the front-end chooses, it needs the back-end settlement to verify and complete the entire payment processing. The payment settlement method requires all participants in the payment system to cooperate and reach a consensus, which usually is time-consuming and troubling.

Payment and settlement through bank account are the most fundamentally used across the world, while there are several centralized problems resulting in high cost and low efficiency, which hinders the further economic development. The first problem is the payment amount limitation. Considering the safety issue, no matter in China or abroad the payment has to under the amount limitation. In China, when you transfer money with mobile banking system or E-bank, the amount is no more than $1,000,000$ RMB every time, and no more than 5,000,000 RMB every day. Although the amount through bank staff can achieve 10.000.000 $\mathrm{RMB}$, the commission is big and you have to spend time on communication. The second problem is that the settlement happens every working day between 17: 15 and 20:30 through settlement system in central bank, which results in delayed payment. Cross-border settlement is the third problem, which is relying on the SWIFT network and correspondent banks to realize the data sharing and recording. This situation is the result that there is no public settlement network where all banks in the world are using. If blockchain is used to formed a network covering all banks, cross-border settlements are easier to deal with. It can reduce the expensive commission for remitting banks and correspondent banks, telecommunication charge in SWIFT, and the cost caused by exchange rate. As there are many actors involving in the centralized payment procedures, the efficiency is influenced, which results in the payment processing is more than 3 working days. The last problem is that it is hard to trace the payment. The complicated and centralized processing of settlement also makes customers confused about the commission.

In modern payment system, card companies and third-party payment also play important roles. When the payment happens in China, card company works as a settlement center between different banks; when it happens cross-border, card company can deal with it faster than bank centralized service as it uses its mechanism. While this payment method is limited to the payments between customers (B2C) not business-tobusiness (B2B), and the payment amount and commission for card company are disadvantages.

The timeliness is improved by independent transfer company, and the value transfer can be implemented within 15 minutes. Compared to traditional bank transfer, independent transfer company has advantage in cross-border payment, while the limitations of the accepted currencies and the high commission cause the unsatisfaction by customers. The settlement between network notes are depending on banks rather than customers.

Third party payment improves the payment efficiency relying on bank settlement system, but the problem of commission is still existing and the irreplaceable bank settlement is controlling the third party, so customers have to be involved in bank system. Besides, the application of third-party payment is not pervasive enough.

To recap briefly, the main problems in current centralized payment methods are high commission; low timeliness; limitations for transfer amount, working hour, currency sort; untransparent payment process; service only for bank customers.

Table 2. Payment methods and settlement models based on blockchain technology

\begin{tabular}{cc}
\hline $\begin{array}{c}\text { Blockchain } \\
\text { technology payment } \\
\text { methods }\end{array}$ & Operating principle \\
\hline Distributed ledger & $\begin{array}{l}\text { Banks establish a } \\
\text { consortium blockchain system } \\
\text { to share data and keep } \\
\text { customers' privacy } \\
\text { Cryptocurrency in } \\
\text { distributed network is used to } \\
\text { peer-to-peer payment and } \\
\text { settlement fryptocurrency } \\
\text { Digital fiat currency is } \\
\text { processed on blockchain with } \\
\text { government endorsement }\end{array}$ \\
\hline Digital fiat currency
\end{tabular}

(Source: Author's own presentation)

Blockchain-enabled decentralized payment and settlement models include the distributed ledger, cryptocurrencies, and digital fiat currency, which are 
demonstrated in the Table 2. Core components of decentralized ledger for cryptographic or synchronisation of databases are widely used in information technology for payments, clearing and settlement. Participants in financial system apply blockchain to propose, validate and update ledgers securely so that transactions may be carried out without necessarily relying on central authorities (Bott \& Milkau. 2017).

Centralization and decentralization are a paradox restricting each other but promoting each other because that the decentralized financial system is working in a centralized political and administrative model, which is a special situation in context of Chinese history. On the one side, China has the long history of centralized feudal societies, on the other side the innovative decentralized blockchain has found a proper market, the research and development are significant in financial industry in the market with Chinese characteristics. Until now, the deployment of this technology is still in a centralized social and economic structure, and the profound exploitation of the decentralization potential is in a long and hard way. However, the support from Chinese government give start-ups confidence. On October 24, 2019, Chinese president Xi Jinping emphasized in a conference that the blockchain is an important breakthrough for Chinese independent innovation in core technologies and encouraged companies to accelerate the blockchain technology development and industrial innovation. The "Hebei Province Blockchain Special Plan (2020-2022)" clarifies that by 2022, there will be 20 leading companies in the blockchain-related fields in Hebei Province, and the government will cultivate a batch of blockchain products including several well-known blockchain brands. More blockchain start-ups are established with the support from government policies.

The decentralized blockchain-enabled payment and settlement system based on peer-to-peer distributed ledger has the advantage of improved efficiency between different banks who establish a consortium blockchain and control the consensus process and share data exclusively, which can be considered partially decentralized, because the right to access the network can be limited to a number of participants (Lewis, 2016). A trustable and immutable distributed ledger established by smart contract makes settlement autonomous without or with less auditing by people. The money is transferred from payor bank to receiving bank directly without third party, thus it releases the complication in cross-border payment and shrinks the settlement time.

Settlement based on cryptocurrency is a new model independent from centralized bank system with the assistance of immutability in blockchain distributed ledger. Cryptocurrency is a new value carrier through digital wallet and it doesn't ask customers must have a bank account. Devices connecting to internet are enough to satisfy the demands in payment and settlement.
Besides, as cryptocurrency is in the form of code thus the process of payment is the transfer of the code, which makes payment and settlement simplified because of the combination of capital flow and information flow, having the advantage of low cost. And the code information is easy to be traced and protected. In China, more cryptocurrencies are designed and experimented to promote its vast application in payment and settlement.

Payment and settlement based on fiat digital currency has the similar advantages to cryptocurrency, which relies on digital wallet and doesn't request bank account. What's more, high efficiency, low cost, traceability, and privacy protection are also involved in this model. Another superiority for fiat digital currency is that it has the government as endorsement to win more public confidence and to be utilized in more situations.

Besides the payment and settlement in financial service, blockchain can change other centralized operating system such as the securities and insurance.

As the securities issued on blockchain can be traded in peer-to-peer network with assistance of smart contract, the time cost is reduced and all transaction data is recorded by all participants safely. Participants can set privilege control and duties for each other. The management of securities is standardized through comprehensive programmed infrastructure to limit the procedures and permission in trade, which is the request of supervision. In 2017, August, "Baidu-Changan Xinsheng-Tianfeng 2017 First Phase Asset Support Special Plan" received certificate by the Shanghai Stock Exchange and is expected to become the first exchange asset securitization product based on blockchain in China.

The issue of trust is most important in insurance industry, and immutability on blockchain can solve this problem very well. The deployment of blockchain in insurance industry is a reasonable tendency as the data on blockchain is irreversible and the process of verification is simplified. If more smart contracts are used, verification becomes autonomous to reduce to labor cost. Claim settlement efficiency is improved as well. Paper insurance documents can be replaced by smart contract to realize the environmental and sustainable development. Data on blockchain is exclusively shared by insurance companies, hospitals, traffic bureau, and other organizations with encrypted data if the data is authorized by customer.

Decentralization is not the idea given by the founder of Bitcoin, nor is it the goal of blockchain technology. Satoshi Nakamoto (2008) described the concept of bitcoin system in the white paper like this: a purely peerto-peer version of electronic cash would allow online payments to be sent directly from one party to another without going through a financial institution (Satoshi, 2008). In fact, he never mentioned the decentralized system for either financial systems or other areas. Decentralization is the process by which the activities of an organization, particularly those regarding planning 
and decision making are distributed or delegated away from a central, authoritative location or group. Decentralization is very complicated to achieve in the present economic situation. So decentralized management can only improve management in financial services but is not the way to replace centralized management, at least not now. The conflict between centralization and decentralization exists at present and will last for the foreseeable future. Many decentralized projects are managed by certain funds or other organizations, which is a characteristic of centralization. Before these projects become decentralized in more significant levels, they have a long way ahead. They have to be distributed then decentralized.

\section{Decentralization VS Centralization}

Centralization is the process that decision-making power moves to a group of people. In a centralized organization, decision right is controlled by a group of people, like the royal family in feudal society. The management class manages most information, data, knowledge and resources; other departments implement the decisions. The management class can control most decisions, and the structure is quite complicated.

Decentralization is the process that decision rights move to broader groups of people (who are considered only doing implementation work) or other subsidiaries and departments. Different departments can have more independent decision rights to design their work practices. Knowledge, information, and other resources are accessed by all members rather than only controlled by the management class.

The advantages of centralization include

1) More resources are available to be used on critical things with better efficiency;

2) Improvement in execution efficiency;

3) The establishment of centralization is the process of selecting the superior and eliminating the inferior, so staffs can be stimulated to work harder.

The disadvantages include

1) The centralized power may cause unsatisfactory results because of the individual decision;

2) The decision efficiency suffers from a large, complex centralized structure.

3) The fixed class division may result in the loss of ambitions.

The advantages of decentralization include

1) Apparent, relative freedom;

2) The elimination of corruption and suppression of absolute power from the centralized structure;

3) More security with the decentralized structure of separate and powerful components;
4) The security also comes from the high cost of attack and manipulation.

And the disadvantages include

1) Too much freedom may result in laziness and low-efficiency in some industries;

2) Slower evolution and optimization of efficiency;

3) Complications in knowing or foreseeing the future of the decentralized organization as there is no centralized leadership.

It is hard to make it clear which of centralized or decentralized management is better considering different organizational situation and turbulent ecosystem. The balance between centralization and decentralization is the essence of this issue. It is about the social structure and economy work in the future.

In Chinese culture, movement generates "Yang"; when its activity reaches extremes, it becomes tranquil. Through tranquillity, the supreme ultimate generates "Yin". When tranquillity has reached its limit, there is a return to movement. Movement and tranquillity, in alternation, become each the source of the other. This alternation is Taichi. Yin and Yang are quite similar to centralization and decentralization; both are two poles of situations. The balance of these two situations is the ideal stage.

Now, with the diversification in the internet services and polycentrism in the governance of social relationship, the decentralized network becomes more apparent than ever. The internet services such as Wikipedia, Flickr, or Blogger provide more forms of high-level of decentralization where anyone can participate, update and share information. The content is more creative, beneficial and diverse. It is useful to increase the enthusiasm of contribution and lower the threshold for production request.

\section{Discussion}

In Chinese culture there was the proverb, "going too far is as bad as not going far enough," and in western culture a similar Western one, "everything in moderation; nothing in excess." It can be traced back to the thoughts of ancient philosophers such as Confucius and Aristotle who had enormous influences in both eastern and western societies. Modern philosophers labelled these principles as the doctrine of the mean or the golden mean (Du and Dai, 2016). The doctrine of the mean with meanings of moderation, rectitude, objectivity, sincerity, honesty and propriety, shows that an individual or organization should pursue a moderate level of achievement and maintain balance and harmony, which is beneficial to have constant equilibrium in work and life (Watson, 2007).

China is a typical collectivist society where the majority of the population have a high level of 
interdependence. The common interest of the group is more important than that of the individual, and people are not encouraged to express ideas that are opposed to the leading social ideology. Besides, personal achievements largely depend on social networks, and the relationship between individuals influences both success and fame (Hofstede, 2001).

At the very beginning of humankind society, decentralization was not suitable; instead, a centralized social and economic system met the need for productivity. Decentralization means less influence from the centralized organizations and would cause new social relationships to which Chinese people do not adapt. The traditional centralized social relationship requests complicated and tense human interactions, which are integral parts of Chinese culture. Less human interactions and social relations but more communication with technology and defined procedures may produce a sense of remoteness among citizens. Emotional attachment is a factor influencing market development, and it is typical nonlinear thinking.

In comparison to linear thinking, which is based on linear cause-effect relationships, nonlinear thinking refers that the output of a given process is not correlated proportionally with the input to the process. It is challenging to escape from the restriction of linear thinking as it contributes substantially to the linearization of our social life (Bolisani and Bratianu, 2018). The smart design and deployment of blockchain technology have guided our life and work to a more efficient and comfortable way; nevertheless, many factors contribute to changing the expected results, emotional attachment is such a factor processing unlimited influence but out of linear metrics.

We should not have the idea that decentralized financial system brought by blockchain will change the financial system soon, considering the issues existing for centuries in society. Those issues include power relations since feudal society. Decentralization is the challenge to the current political centralization, and blockchain technology is the tool used to realize better governance. When there is an apparent conflict between governance and management, the members of vested interest groups will not allow further change. There is a long and arduous process before the implementation of decentralization in social relationships. No matter how smart and resilient the new technology is, it belongs, in essence, to computation. Management is a human-being behavior, including nonlinear emotional attachment and relations. The way that people understand and use blockchain technology to make the balance between centralization and decentralization is a long-term route of discovery. Not only the knowledge of technology, but also cultures must be involved in this theoretical and empirical adventure.

Besides the issue of power relations, we have to see that there are other difficulties and obstacles to the widespread adoption of blockchain technology in financial and other domains, including

1) Regulatory uncertainty.

2) Lack of trust among users,

3) Ability to bring networks together,

4) Separate blockchains not working together,

5) Inability to scale,

6) Intellectual property concerns,

7) Compliance concerns (PWC., 2018).

Among these obstacles, the regulatory uncertainty and lack of trust among users are the most challenging ones. For a new technology that can completely change the traditional operations in financial services and many other areas, it is typical for people to have a negative attitude and attempt to stop its development. The procedures to have detailed and comprehensive laws and regulations are complicated. The history of the internet, from its creation to its acceptance by customers and markets, is quite long and hard. In order to overcome these difficulties, governments and businesses should make cooperation to deal with the challenges.

Some basic understandings are helpful for the managerial implications in decentralized governance.

Firstly, the relationship between centralization and decentralization is a symbiosis relationship. Each has advantages and disadvantages. They can make up the shortcomings of one with the strengths of the other. Throughout history, industries, domains, and businesses have had different functions. In management, for various purposes, the deployment of centralization or decentralization can be favoured.

Secondly, for decentralization, systems thinking is beneficial as in traditional management processes, various variables are involved in determining results. For example, the situations in different countries and areas, the periods, and scale of decentralization. According to Peter Senge (1999), systems thinking is more significant than ever due to the overwhelming complexity (Senge, 1999). In this society, far more information is created, greater interdependency and changes are happening out of our management. Systems thinking is a discipline to see the whole picture. It is a framework for seeing interrelationships rather than things themselves. Decentralization works with centralization as a whole. No one can exist alone. When we apply decentralization in this data-driven society, centralization must always keep its influence. The rules and regulations of supervision of blockchain technology deployment and the lays for tokens management are developed and carried out correspondingly to the decentralized projects.

Thirdly, the form an enthusiastic attitude to the innovation of blockchain technology that has brought change to conventional financial services with the features of distributed digital ledger and transparent details of value transfers. Decentralization in financial 
services embodies fewer controls and limitations from government and financial institutes. When we enjoyed the convenient and comfortable life, we have to notice the limitations. This technology is not developed enough to be utilized on a large scale to deal with unexpected situations and problems. In essence, Blockchain is merely sophisticated mathematical software. The complex situations caused by humans need more flexible solutions than traditional algorithms. Take Bitcoin as an example; it was first designed and deployed to realize the benefits from decentralization for a peer-to-peer payment mechanism. The reality nowadays is that the most powerful mining pools are controlled by a small number of people, which is in contradiction to the original intent of decentralization because it is influenced by many uncontrolled and profound factors including political, economic and cultural reasons.

For a more decentralized society and financial system, we can have some strategies ready for when blockchain-enabled decentralized projects start coming.

First, we can learn from the Golden Mean in Confucianism or Zhongyong, which is the character or virtues of always maintaining and doing the right thing, not more nor less, but just the right degree, of behaviour, irrespective of external pressures. When it comes to blockchain project management, decentralized and centralized management should be deployed in a balanced measure. We should make full use of them wisely, and not allow one to replace the other completely. The degree of decentralization and the progress of it play an essential role in the success of projects.

Second, it is significant to have strategic clarity for the development of blockchain initiatives. The decentralized management in financial services nowadays is reflected mainly by Blockchain-related financial projects. In order to mitigate risk in this new area, managers should not begin with the big-bang, change-the-world ideas; instead, they should try to build confidence by starting smaller.

Third, the balanced management considering blockchain technology in financial services and other aspects should focus on creating an ecosystem where interoperability is a vital part of successful blockchain management. If different participants have data and transactions in the Blockchain, that data has to be standardized, and its governance must be robust. For example, standard naming conventions and system-wide data models, to which all parties will agree to adhere, have to be developed. Besides, scalability is another indispensable factor for a successful blockchain project. In this globalized economic system, scalability is an issue that a group of companies can best address by collective capabilities and power. Significant scalability concerns also relate to the technology itself. The technology's scalability is a critical area to monitor as it rapidly evolves. The power to influence is only effective when procedures of projects are designed in operational safety structures and are occupied by people with requisite competencies (Monteiro et al., 2019).

Fourth, enthusiasm is a key point no matter which degree of decentralized management has achieved. Managers, customers, workers, staffs, public servants, they are all human beings, and the development of blockchain technology and decentralized management are given the goal to make people's lives better. People involved in blockchain projects should always keep their enthusiasm to enhance the deployment of this technology and the management way to promote the development of this society. Energy management, like power management, has applied blockchain technology to improve the flexibility of energy distribution. Blockchain technology has great potential for accelerating the decentralization of large and complex systems such as power systems. The decentralized capability of Blockchain allows implementing bottomup solutions, without depending on grid operators or waiting for changes in policies (Cutsem et al., 2019).

Last but not least, governments and business should navigate reasonable regulations and strategies. No matter how the situation changes, the research and attempts in blockchain projects and decentralized management are always valuable for management and economic development. Companies should anticipate how regulators might respond to commercial activities migrating to a blockchain project. Managers should keep abreast of regulatory developments and engage with lawmakers at all jurisdictional levels, and focus on the changes in regulations and the blockchain market. To set up labs and test points in more friendly locations can ensure companies more successful experimentation with fewer legal restrictions and regulations.

In recent years, new industries and areas besides financial services have deployed blockchain technology for establishing a decentralize financial system where more opportunities emerging but little or no regulation related to Blockchain, such as industrial products, retail and energy. Furthermore, the functions of blockchain technology in data transparency and secure data recording are significant for regulation makers. With this technology, not only companies but also regulators can have transparent and correct access to data, and all the amendment of regulations or other data can be recorded which is convenient for monitoring and following schedule. To make progress in blockchain management, we should have the belief that more strategies will be defined for the Blockchain's operating rules and developing the incentives for future participants.

\section{Conclusions}

The primary motivation of this article is to explore the development and practice of decentralization in ancient Chinese history and modern financial services, to research the connection and relationship between 
centralization and decentralization. For decentralized projects management, we put forward some understandings and strategies.

The article first goes to the theoretical inquiry in the concept of decentralization and the types according to different criteria. Generally, decentralization is divided into political decentralization, administrative decentralization, fiscal decentralization and market or economic decentralization. With the difference in the degree of decentralization, there are three levels: devolution, delegation, deconcentration. With the difference of the number of physical computers and nodes in Blockchain, numbers of individuals or organizations managing nodes, and the number of interfaces and data structures, decentralization in the internet world is divided into three kinds. However, generally speaking, users become internet nodes and connect to others equally without the control from the centre.

After that, this article focuses on the development of decentralization in the context of Chinese history. With the timeline of unified and disunified dynasties, as well as the economy in different periods, we found that the centralized, unified dynasties enjoyed more prosperous productivity and economy. In ancient feudal societies, centralization played a more important role in the economy. The reasons are explained in part through the economic situation in Chinese history. It is found that when the population of a nation is small, and the economy of scale is far from either centralized or decentralized management, a peaceful and harmonious society promises people a good life. With the development of productivity, there appeared immigration, business, and dominating hierarchy, and the vested interests group established the centralized authority entity promoted the development of the economy. In an agricultural society, the centralization met the needs of people and society properties.

In modern society, especially this digitalized world, a centralized structure cannot meet the request of history. With Bitcoin and blockchain as representative technologies, decentralized management becomes more compelling, especially in financial services. The properties of blockchain technology, including decentralization, transparency, security and efficiency, has brought traditional financial services changes. More and more related projects are showing the significance of decentralization. The experimental practices of blockchain technology in payment, settlement, insurance industry and securities service demonstrate the potential of decentralize management. And the favorable policies from government make the future promising. Nevertheless, we should not split centralization and decentralization independently to analyze, what we have to understand is that both have their advantages to promote the development of society and economy in different periods. When one shows its weakness, it is easier for people to find the strengths of the other and work more for it. The comparison between these two mechanisms in advantages and disadvantages embodies many details.

When we face the decentralization in this digitalized society, positive attitude and correct understanding are essential. When we notice the strength of it, we should also understand its limitations. For managers, the key is to control the degree of decentralization. In modern society, with rapid and widespread development of technology, decentralization can be showed in complicated and diverse forms, and blockchain technology has made it more practical in management and economics. Among blockchain projects, the top two difficulties are the issue of trust in new technology and regulatory uncertainty. For better decentralization governance, companies should have a clear and correct understanding of the practical relationship between decentralization and centralization, and cooperate with other companies in the same industry to build a sustainable ecosystem. When facing regulatory uncertainty, confidence is necessary as well as the sensitive reaction to new laws and regulations.

It is too early to predict how society will evolve with blockchain technology and the idea of decentralization, but the changes always meet the requests from human beings and the world, and blockchain technology has more stages in various industries to show.

\section{References}

Ahmad. M. S. \& Talib. N. B. A., 2011. Decentralization and Participatory Rural Development: A Literature Review. J. Contemp Oncol. Vol.5.Issue 4. 2011. 58-67.

Anastasiia. L. 2019. Blockchain Architecture Basics: Components, Structure, Benefits and Creation. Access: https://mlsdev.com/blog/156-how-to-build-your-ownblockchain-architecture.

Bolisani. E. \& Bratianu. C. 2018. Emergent Knowledge Strategies. Strategic Thinking in Knowledge Management. Springer.

Bott. J. and Milkau. U., 2017. Central bank money and blockchain: A payments perspective. Journal of Payments Strategy \& Systems. Volume 11. Number 2.

Bulut. E. \& Abdow. B1. 2018. Decentralization and Poverty Reduction: Opportunities and Challenges in Kenya. J. Sosyoekonomi, 2018, Vol. 26(36), 179-196

Buterin. V., 2017. The Meaning of Decentralization. Retrieve: https://medium.com/@VitalikButerin/the-meaning-ofdecentralization-a0c92b76a274

Castelfranchi. C., 2004. Trust Mediation in Knowledge Management and Sharing. International Conference on Trust Management, 2003 Volume: iTRUST.

Chatsko. M., 2018. Smart Contracts and the Blockchain, Explained. Retrieve: https://www.fool.com/investing/2018/03/09/smartcontracts-and-the-blockchain-explained.aspx

Chen.Y, Bellavitis. C. 2019. Blockchain disruption and decentralized finance: The rise of decentralized business models. Journal of Business Venturing Insights. 
Cutsem. O. V, Dac. D. H., Boudou. P., Kayal. M. 2019. Cooperative energy management of a community of smart-buildings: A Blockchain approach. Electrical Power and Energy Systems 117 (2020).

Du. K. \& Dai. Y. 2016. The doctrine of the mean: Reference groups and public information systems development. Journal of Strategic Information Systems 27 (2018) 257273.

Fye. A. 2017. Significance of fiscal decentralization: The Gambia at a glance. Net Journal of Business Management Vol. 5(1), pp. 6-18.

Hobbes. T., 1651. LEVIATHAN, or the matter, forme and power of a commonwealth ecclesiasticall and civil. By Thomas Hobbes of Malmesbury London.

Hofstede. GH 2001. Culture's consequences: Comparing values, behaviours, institutions, and organizations across nations, first ed. Sage Publications, Thousand Oaks, CA.

Kelly. K. 1994. Out of Control: The New Biology of Machines, Social Systems, and the Economic World by. Basic Books.

Lewis. C., 2016. BLOCKCHAIN Your Comprehensive Guide to Understanding the Decentralized Future. Retrieve: https://www.scribd.com/document/359056038/Christoph er-Lewis-Blockchain-your-comprehensive-guide-tounderstanding-the-decentralized-future-epub

Liu. X.L., Wang. W.M., Guo. H., Barenjia. A. V., Zhi Lia, Huang. G. Q. 2020. Industrial Blockchain based framework for product lifecycle management in industry 4.0. Robotics and Computer Integrated Manufacturing 63

Lü. S. 2016. Zhongguo Tongshi. (Chinese Civilization). China Overseas Chinese Press.

Niekerk. M.V., 2016. First Financial Institution in Europe to Launch a Blockchain Based App Publicly. Retrieve: https://themerkle.com/first-financial-institution-ineurope-to-launch-a-blockchain-based-app-publicly/

Monteiro. G. P, Hopkins. A., Melo. PFF 2019. How do organizational structures impact operational safety? Part 2 -Designing structures that strengthen safety. Safety Science 123 (2020).

Müller. B. E., Elsman. M., Henglein. F., Ross. O., 2017. Automated Execution of Financial Contracts on Blockchains. Retrieve: https://www.researchgate.net/publication/321327355

Pazaitis. A., Filippi. P.D., Kostakis. V. 2017. Blockchain and value systems in the sharing economy: The illustrative case of Backfeed. J. Technol Forecast Soc Change. 125 (2017) 105-115

PWC. 2018. Blockchain is here. What's your next move? PwC's Global Blockchain Survey 2018.

Rousseau. J-J., 1762. Du Contrat Social, Principes du droit politique (The Social Contract, Principles of Political Right). The ISN ETH Zürich.

Satoshi. N. 2008. Bitcoin: A Peer-to-Peer Electronic Cash System. https://bitcoin.org/en/bitcoin-paper (visited on 19/08/2019)

Schneider J, Blostein A, Lee B, Kent S, Groer I, Beardsley E., 2016. Blockchain-putting theory into practice. Retrieve: http://www.finyear.com/attachment/690548/.

Senge. P. 1999. The fifth discipline: The art and practice of the learning organization. London: Random House.
Swan. M. 2015. Blockchain: Blueprint for a New Economy. O'Reilly Media, Sebastopol.

Watson. B. 2007. The Analects of Confucius: Translations from the Asian Classics. Columbia University Press, New York.

Work. R. 2002. Overview of Decentralisation Worldwide: A Stepping Stone to Improved Governance and Human Development. 2nd International Conference on Decentralisation Federalism: The Future of Decentralizing States? 25-27 July 2002 Manila, Philippines.

Zhang. Y., Fan G., Whalley J. 2015. Economic Cycles in Ancient China. Nber Working Paper Series. Jel No. N1,N15. 2015. Nber Working Paper No. 21672 